\title{
Lung dendritic cells and IgE: the link between virus and a topy
}
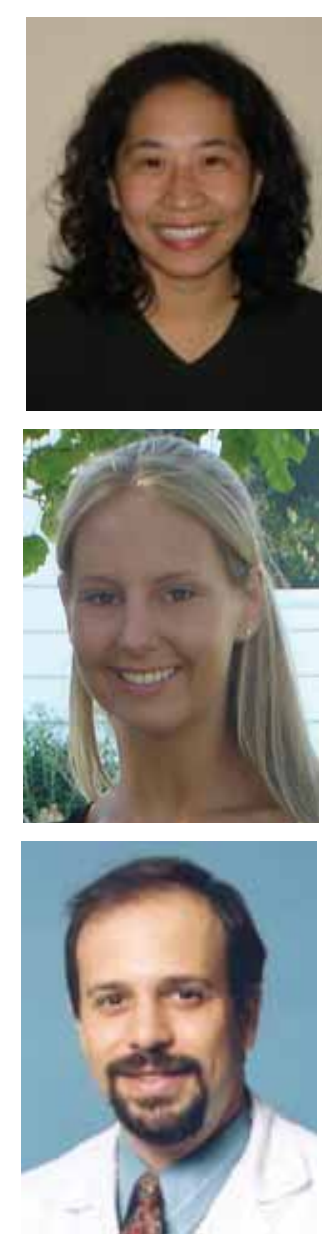

StaphenieS Park, SarchJ Ehlenbedh \& Mitchell H Grayson'

${ }^{\dagger}$ Author for correspondence M edical College of Wisconsin, M ACC Fund Research Center, Room 5075, 8701 Watertown Plank Road, Milwaukee, WI 53226, USA Tel.: +1 4144565648 ; Fax: +1 414456 6487; wheeze@allergist.com '...the virus-FceRl-a topy axis certa inly appears to provide much promise for understanding how and why atopic diseases develop, and more importantly, what could

be done to prevent them...'

Atopic diseases, including asthma, have been increasing in the modernized world, reaching epidemic proportions [1,2]. The reasons for this increase are not known. Some have proposed that a decrease in bacterial infections associated with improved public health may be the culprit [3]. The 'hygiene hypothesis', as this theory is called, fails to take into account the fact that some pathogens, particularly viral infections, are associated with increased risks of asthma and atopic disease [3-5]. In particular, severe paramyxoviral infections have been implicated in the development of asthma. The best example of this is respiratory syncytial virus (RSV). RSV is a common pathogen that infects nearly all children by 2 years of age [6]. However, infants who require hospitalization because of a severe RSV infection have been shown to have over a 20-fold greater risk of developing asthma compared with nonhospitalized infants [7]. Furthermore, RSV, parainfluenza, influenza and rhinovirus have been shown to be major causes of asthma exacerbations [8]. In addition to the risk for asthma, many viral infections have been noted to induce production of $\mathrm{IgE}$, although the reason why IgE is produced is unknown [9-16]. The amount of IgE produced has correlated with clinical parameters, including risk of subsequent wheezing in infants and otitis media with effusion in children [9-13,17]. Why a Th1-biased antiviral response would predispose to atopic disease, a Th2-biased response, is not clear, nor is it clear why a Th1 response would lead to production of IgE, the quintessential Th2-biased antibody.

Atopy \& paramyxoviral infections: the model Using a mouse model of viral-induced asthma, we recently explored a potential mechanism that may link the antiviral Thl response to the subsequent
Th2-atopic response, specifically focusing on the role IgE may play in the development of postviral atopic disease. Because RSV does not cause productive infection in mice, we used an experimental model of asthma that utilizes Sendai virus (SeV). This virus, a natural rodent pathogen, can lead to mouse death, and in the inoculum used in the model usually produces a severe illness with 20\% weight loss from which the mice recover [18-19]. SeV, like RSV, is a paramyxovirus and studies have shown similar immune responsiveness and pathology with RSV [18-22]. M ice typically clear SeV approximately days 10-12 postinoculation, but demonstrate lower airway inflammatory changes and airway hyper-reactivity, similar to human asthma, for at least 1 year after infection. Evidence also exists that $\mathrm{SeV}$ infection, in addition to the expected Th1 response, induces a Th2 profile as well. In fact, some lymphocytes recruited to the lungs around the time of virus clearance (days 10-12) have been shown to produce the Th2 cytokine IL-13 and express the Th2 transcription factor Gata-3 by day 21 postinoculation $[19,23]$. SeV infection, like most other viral infections, also leads to the production of $\mathrm{IgE}$, a hallmark Th2-mediated antibody response [4].

'Using a mouse model of vira l-induced asthma, we recently explored a potential mechanism that may link the antiviral Th1 response to the subsequent Th2 a topic response...'

Given that IgE is made during the antiviral response, we undertook studies to determine what would happen during a viral infection in mice genetically deficient in the high affinity receptor for IgE, $F c_{\varepsilon} R I$. Somewhat surprisingly, mice deficient in $\mathrm{F} c_{\varepsilon} \mathrm{RI}$ failed to develop postviral mucous cell metaplasia [4].

Our investigation identified lung dendritic cells as critical intermediates in the development of postviral atopic disease [24-25]. There are two broad types of dendritic cells: the plasmacytoid dendritic cells $(\mathrm{pDC} C \mathrm{~s}$ ) and the conventional dendritic cells ( $C D C s)$. U pon stimulation, the $p D C s$ secrete large quantities of type I interferon (IFN ; 
and to a lesser extent IL-12) and are thus important in the antiviral response. $C D C s$, on the other hand, are the primary antigen-presenting cells as they take up antigens such as viral particles, process them into smaller peptides and present them to $T$ cells in the draining lymph node, resulting in proliferation of virus-specific $T$ and $B$ lymphocytes. Those virus-specific $T$ cells are then recruited to the lung and the formation of virus-specific antibodies from $B$ cells represent the culmination of the antiviral response.

H owever, it has also been shown that presentation of antigen in the draining lymph node can only occur in the first 24-30 h of viral infection $[24,26]$. Beyond that window, CDCS no longer migrate back to the lymph node regardless of any stimulation and will remain in the lung for up to 5 days [26]. It does appear that these stationary $C D C s$ are capable of antigen presentation in the periphery, as they express maturation and differentiation markers [24].

'...we have now demonstrated a potential mechanism linking virus and atopy where severe paramyxoviral infection leads to Fc $\mathrm{RRI}$ expression on CDCs through the type I IFN receptor.'

In the setting of a severe viral infection, CD C s in the lung parenchyma (i.e., those that do not migrate to the draining lymph node) express $\mathrm{FC \varepsilon RI}$ in addition to MHC II and co-stimulatory molecules [4]. Interestingly, expression of $\mathrm{F} C \varepsilon \mathrm{RI}$ on lung $\mathrm{CDC}$ s precedes the development of virus-specific IgE production, although its expression on lung $C D C S$ is type I IFN receptor dependent [4]. The fact that the receptor appears before IgE production is somewhat contrary to the usual understanding that IgE levels drive $\mathrm{F} c_{\varepsilon} \mathrm{RI}$ expression, at least on human basophils, mast cells and dendritic cells [27-31]. The critical importance of $\mathrm{CDC}$-expressed $\mathrm{FC} \mathrm{RI}$ was demonstrated by the fact that transfer of wildtype CD C s (cells that were capable of expressing $F_{C \varepsilon R I)}$ into $F C_{\varepsilon} R I$-deficient mice before viral infection restored the normal postviral mucous cell metaplasia [4].

To determine a mechanism by which $\mathrm{F}_{\mathrm{C} \varepsilon \mathrm{RI}}$ on lung $C D C s$ could modulate mucous cell metaplasia, we explored the effect of cross-linking the high affinity receptor with antigen. The reasoning behind this experiment was that $F_{\varepsilon} R I$ expressing lung $C D C s$ should have been able to bind viral-specific IgE when it was made. Because both of these events happened before virus was normally cleared (i.e., before day 10-12), there would still be virus in the lung. Therefore, the virus-specific IgE (bound to CD C $\mathrm{F}(\varepsilon \mathrm{RI})$ should have been able to bind virus, cross-linking the receptor. Interestingly, we found that cross-linking $\mathrm{F} C \varepsilon \mathrm{R}$ I on lung $C D$ C sled to the production of CCL28, a $\beta$-chemokine [4]. $\mathrm{CCL}_{28}$ is a CD $4^{+}$and $\mathrm{CD} 8^{+} \mathrm{T}$-cell chemoattractant that is able to recruit Th2 cells in an antigen-independent fashion [32]. The importance of CCL28 has been shown in murine models of asthma where blockade of CCL28 prevented airway infiltration by eosinophils, as well as airway hyper-reactivity [33-34]. Furthermore, in humans, CCL28 has been shown to be elevated in the lungs of patients with asthma [35]. The receptors for CCL28, CCR3 and CCR 10 are found on a variety of cells critical to asthma pathogenesis (including eosinophils, Th2 cells, Treg cells and natural killer T cells) [33,35-38]. Thus, it seems that CCL28 may regulate the activity of inflammatory cells that are critical to the atopic response. Indeed, in the SeV model, the development of postviral mucous cell metaplasia has been shown to be dependent on Th2 IL-13 production [19]. It seems plausible, therefore, that the lack of mucous cell metaplasia in mice deficient in $\mathrm{F} \mathrm{C}_{\varepsilon} \mathrm{RI}$ was simply due to a failure of CCL28 mediated recruitment of Th2 cells to the lung post-SeV inoculation. Indeed, supporting this idea, we found the frequency of IL-13 mRN A containing Th2 cells reduced in the lungs of $F C_{\varepsilon} R I$-deficient mice [4].

Therefore, we have now demonstrated a potential mechanism linking virus and atopy where severe paramyxoviral infection leads to $\mathrm{FC} \varepsilon \mathrm{RI}$ expression on $\mathrm{CDCS}$ through the type I IFN receptor. This pathway is outlined in Figre1, where cross-linking of CDC-expressed $\mathrm{FC} R \mathrm{RI}$ results in CCL28 secretion, leading to recruitment of CD 4+ Th2 cells, and ultimately IgE production and IL-13-dependent mucous cell metaplasia - two critical components of the atopic response.

\section{Therapeutic implications}

This novel pathway not only increases our understanding of atopic disease, but also creates opportunities for therapeutic intervention. O ne promising target could be blocking $F(\varepsilon R I$ expression on $C D C S$ in the lung during a viral response, as this might prevent C C L28 production, recruitment of $\mathrm{Th} 2$ cells to the lung and, finally, postviral atopic disease. These CDCS are particularly appealing in that $F C_{\varepsilon} R I$ is only 
Figure 1. Novel paradigm for induction of postviral atopic disease.

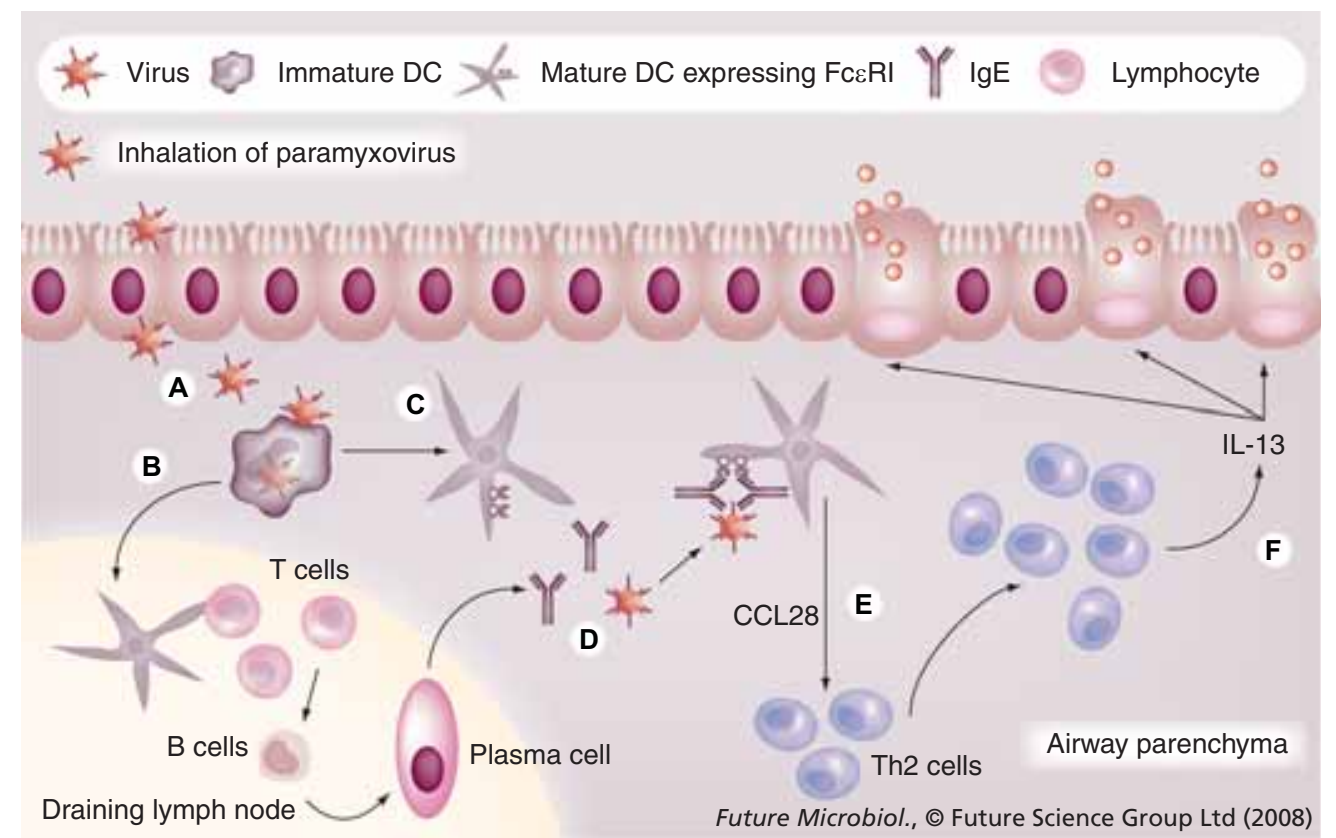

(A) Inhalation of a paramyxovirus leads to productive infection of the airway epithelium. Immature DCs in the airway take up viral particles. (B) These DCs process the particles and migrate back to the draining lymph nodes, leading to expansion of viral-specific $T$ cells. These $T$ cells may instruct B cells with antibody specificity for viral particles to make antibodies against the virus. Some of these B cells will become plasma cells and make IgE against the virus. (C) Those DCs that remained in the lung and did not migrate to the lymph node become mature and express the high affinity receptor for $\lg E\left(F_{\varepsilon} R I\right)$. (D) Antiviral $\lg E$ will bind DC-expressed FC $\varepsilon$ Rl followed by viral particles binding this IgE. (E) The effect of this cross-linking of FC\&RI on DCs is the production of CCL28, a chemoattractant that will bring Th2 cells into the lung in an antigen nonspecific fashion. (F) These Th2 cells are capable of producing IL-13, which leads to transdifferentiation of airway epithelial cells into mucous-producing cells, thus fully translating the viral infection into a Th2-mediated atopic disease.

DC: Dendritic cell.

expressed after the onset of viral symptoms and therefore the therapeutic intervention could be limited to the small population of cells in the lung, leaving those $C D C s$ migrating back to the draining lymph node unaffected. Of course, we still do not fully understand the mechanisms behind $C D C F C \varepsilon R I$ expression in the mouse, let alone the human, so this intervention must await greater study.

Currently, a monoclonal antibody against IgE has become available and is now used as a treatment for atopic disease [39-41]. Anti-IgE functions to bind and remove IgE from circulation, preventing the IgE from binding $\mathrm{F} C \varepsilon \mathrm{R} I$ on mast cells, basophils and $C D C s$, preventing the usual clinical effects of allergy. In our novel pathway, anti-IgE could have a potential role as well. Since IgE is produced as the severe viral infection reaches its peak, just prior to improvement in symptoms (based on the mouse model), administration of anti-IgE at (or just before) this time should block the antiviral IgE from ever binding to $C D C$ F $C \varepsilon R I$. This would prevent C CL28 production and the downstream events. H owever, before this therapy can be recommended, a better understanding of the natural role of IgE in severe viral infections needs to be elucidated. IgE may be important in the downregulation of the antiviral response and blockade of IgE may worsen inflammation or result in persistent infection. O ur studies in $\mathrm{F}_{\varepsilon} \mathrm{RI}-$ and $\mathrm{IgE}$-deficient mice have not supported these possibilities, as the mice did not appear to have increased disease (data not shown). Nevertheless, much more research must be undertaken before anti-I gE can be recommended as a therapy to prevent virus-induced atopic disease.

A final target for blockade identified from these studies is CCL28. Again, we do not know the functional significance of CCL28 in an ongoing antiviral response; although our experience with the rodent model does not suggest that 
it is necessary for survival from the viral insult. Future studies will help shed light on the normal role of this chemokine in lung physiology.

\section{Conclusion}

An explanation for the increasing prevalence of atopic diseases remains elusive. Several different factors have been implicated, including viral infections. W hile this association between virus and atopy has been established, no mechanistic link had been identified until recently. O ur recent data has uncovered a novel pathway linking severe paramyxoviral infection and the development of atopy through $\mathrm{F} C \varepsilon \mathrm{R} I, C D C$ and CCL28. The functional consequences of this pathway remain unknown and the pathway has yet to be demonstrated in humans. N evertheless, the virus- $\mathrm{F} c_{\varepsilon} \mathrm{R} I$-atopy axis certainly appears to provide much promise for understanding how and why atopic diseases develop, and more importantly, what could be done to prevent them.

Financial \& competing interests disclosure MH Grayson has served as a consultant for N ovartis and $\mathrm{Genentech}$, and is on the speaker's bureau for M erck and $\mathrm{C}$. $\mathrm{He}$ has received research grants from $\mathrm{N}$ ovartis $/ \mathrm{G}$ enentech and the $\mathrm{N}$ ational Institutes of $\mathrm{H}$ ealth. The authors have no other relevant affiliations or financial involvement with any organization or entity with a financial interest in or financial conflict with the subject matter or materials di scussed in the manuscript apart from those disclosed.

No writing assistance was utilized in the production of this manuscript.

\section{Bibliography}

1. Sly RM : Changing prevalence of allergic rhinitis and asthma. Ann. Allergy Asthma Immunol. 82, 233-248; quiz 248-252 (1999).

2. N ational Asthma Education and Prevention Program. Expert panel report: guidelines for the diagnosis and management of asthma update on selected topics - 2002. J. Allergy Clin. Immunol. 110, S141-S219 (2002).

3. von M utius E: Allergies, infections and the hygiene hypothesis - the epidemiological evidence. Immunobiology 212, 433-439 (2007).

4. Grayson M H , Cheung D, Rohlfing M M et al.: Induction of high-affinity IgE receptor on lung dendritic cells during viral infection leads to mucous cell metaplasia. J. Exp. M ed. 204, 2759-2769 (2007).

5. Grayson $\mathrm{M} \mathrm{H}, \mathrm{H}$ oltzman $\mathrm{M} \mathrm{J}$ : Emerging role of dendritic cells in respiratory viral infection. J. M ol. M ed. 85, 1057-1068 (2007).

6. M eissner H C: Reducing the impact of viral respiratory infections in children. Pediatr. Clin. N orth Am. 52(6), 695-710 (2005).

7. Sigurs N, Bjarnason R, Sigurbergsson $F$, Kjellman B, Bjorksten B: Asthma and immunoglobulin $E$ antibodies after respiratory syncytial virus bronchiolitis: a prospective cohort study with matched controls. Pediatrics 95, 500-505 (1995).

8. Kusel M M, de Klerk NH, Kebadze T et al.: Early-life respiratory viral infections, atopic sensitization, and risk of subsequent development of persistent asthma. J. Allergy Clin. Immunol. 119, 1105-1110 (2007).

9. Alexeyev $O A, A$ hlm $C$, Billheden J, Settergren B, Wadell G, Juto P: Elevated levels of total and puumala virus-specific immunoglobulin E in the Scandinavian type of hemorrhagic fever with renal syndrome. Clin. Diagn. Lab. Immunol. 1, 269-272 (1994).

10. Calenoff $E$, Zhao JC, D erlacki $E L$ et al.: Patients with meniere's disease possess IgE reacting with herpes family viruses. Arch. O tolaryngol. H ead N eck Surg. 121, 861-864 (1995).

11. Koraka $P, M$ urgue $B, D$ eparis $X$ et al.: Elevated levels of total and dengue virusspecific immunoglobulin $E$ in patients with varying disease severity. J. M ed. Virol. 70, 91-98 (2003).

12. Votava M, Bartosova D, Krchnakova A, Crhova K, Kubinova L: Diagnostic importance of heterophile antibodies and immunoglobulins IgA, IgE, IgM and lowavidity IgG against Epstein Barr virus capsid antigen in children. Acta Virol. 40, 99-101 (1996).

13. Welliver RC, Sun M, Rinaldo D, O gra PL: Predictive value of respiratory syncytial virus-specific IgE responses for recurrent wheezing following bronchiolitis. J. Pediatr. 109, 776-780 (1986).

14. Las H eras J, Swanson VL: Sudden death of an infant with rhinovirus infection complicating bronchial asthma: case report. Pediatr. Pathol. 1, 319-323 (1983).

15. Rager KJ, Langland JO, Jacobs BL, Proud D, $M$ arsh D G, Imani F: Activation of antiviral protein kinase leads to immunoglobulin $\mathrm{E}$ class switching in human B cells. J. Virol. 72, 1171-1176 (1998).

16. Skoner D P, D oyle W J, Tanner EP, Kiss J, Fireman P: Effect of rhinovirus 39 (RV-39) infection on immune and inflammatory parameters in allergic and non-allergic subjects. Clin. Exp. Allergy 25, 561-567 (1995).
17. Chantzi FM , Kafetzis D A, BairamisT et al.: IgE sensitization, respiratory allergy symptoms, and heritability independently increase the risk of otitis media with effusion. Allergy 61, 332-336 (2006).

18. Walter MJ, M orton JD, Kajiwara N, Agapov E, H oltzman M J: Viral induction of a chronic asthma phenotype and genetic segregation from the acute response. J. Clin. Invest. 110, 165-175 (2002).

19. Tyner JW, Kim EY, Ide K et al.: Blocking airway mucous cell metaplasia by inhibiting EGFR antiapoptosis and IL-13 transdifferentiation signals. J. Clin. Invest. 116, 309-321 (2006).

20. Walter M J, Kajiwara N , Karanja P, Castro M , H oltzman M J : Interleukin 12p40 production by barrier epithelial cells during airway inflammation. J. Exp. M ed. 193, 339-351 (2001).

21. Patel AC, M orton JD, Kim EY et al.: $G$ enetic segregation of airway disease traits despite redundancy of calcium-activated chloride channel family members. Physiol. Genomics 25, 502-513 (2006).

22. Johnson JE, Gonzales RA, O Ison SJ, Wright PF, Graham BS: The histopathology of fatal untreated human respiratory syncytial virus infection. M od. Pathol. 20, 108-119 (2007).

23. Tyner JW, U chida $\mathrm{O}$, Kajiwara $\mathrm{N}$ et al.: $\mathrm{Ccl} 5 / \mathrm{C}$ cr5 interaction provides antiapoptotic signals for macrophage survival during viral infection. $\mathrm{N}$ at. M ed. 11, 1180-1187 (2005).

24. Grayson M H, Ramos M S, Rohlfing M M et al.: Controls for lung dendritic cell maturation and migration during respiratory viral infection. J. Immunol. 179, 1438-1448 (2007). 
25. Grayson $\mathrm{M} \mathrm{H}$ : Lung dendritic cells and the inflammatory response. Ann. Allergy Asthma Immunol. 96, 643-651; quiz 652-643, 678 (2006).

26. Legge KL, Braciale T]: Accelerated migration of respiratory dendritic cells to the regional lymph nodes is limited to the early phase of pulmonary infection. Immunity 18, 265-277 (2003).

27. Sarbjit SS, M acG lashan D Jr: H ow IgE upregulates the allergic response. Curr. 0 pin. Immunol. 14, 694-697 (2002).

28. M acG lashan $D$ Jr, Bochner $B$, Adelman $D$ et al.: D own-regulation of $F C_{\varepsilon} R I$ expression on human basophils during in vivo treatment of atopic patients with anti-IgE antibody. J. Clin. Immunol. 158, 1438-1445 (1997).

29. $M$ aurer $D$, Ebner $C$, Reininger $B$ et al.: The high affinity $I g E$ receptor $\left(F C_{\varepsilon} R 1\right)$ mediates IgE-dependent allergic presentation. J. Immunol. 154, 6285-6290 (1995).

30. Foster B, M etcalfe D D, Prussin C: H uman dendritic cell 1 and dendritic cell 2 subsets express FC\&R 1: correlation with serum IgE and allergic asthma. J. Allergy Clin. Immunol. 112, 1132-1138 (2003).

31. H su C, M acG lashan D Jr: IgE antibody up-regulates high affinity IgE binding on murine bone marrow-derived mast cells. Immunol. Lett. 52, 129-134 (1996).

32. Stephens R, Chaplin D D : IgE cross-linking or lipopolysaccharide treatment induces recruitment of Th2 cells to the lung in the absence of specific antigen. J. Immunol. 169, 5468-5476 (2002).
33. English K, Brady C, Corcoran P, C assidy JP, $M$ ahon BP: Inflammation of the respiratory tract is associated with ccl28 and ccr10 expression in a murine model of allergic asthma. Immunol. Lett. 103, 92-100 (2006).

34. John AE, Thomas M S, Berlin AA, Lukacs N W: Temporal production of ccl28 corresponds to eosinophil accumulation and airway hyperreactivity in allergic airway inflammation. Am. J. Pathol. 166, 345-353 (2005).

35. Wang W, Soto H, O Idham ER et al.: Identification of a novel chemokine (ccl28), which binds ccr10 (gpr2). J. Biol. Chem. 275, 22313-22323 (2000).

36. Kay AB: Allergy and allergic diseases. First of two parts. N. Engl. J. M ed. 344, 30-37 (2001).

37. Kearley J, Barker JE, Robinson DS, Lloyd CM : Resolution of airway inflammation and hyperreactivity after in vivo transfer of $C D 4+C D 25+$ regulatory $T$ cells is interleukin 10 dependent. J. Exp. M ed. 202, 1539-1547 (2005).

38. M eyer EH, Goya S, Akbari $O$ et al.: Glycolipid activation of invariant $T$ cell receptor ${ }^{+} \mathrm{NK}$ T cells is sufficient to induce airway hyperreactivity independent of conventional $C D 4^{+} T$ cells. Proc. $N$ atl Acad. Sci. USA 103, 2782-2787 (2006).

39. Bousquet J, Wenzel S, H olgate S, Lumry W, Freeman $\mathrm{P}, \mathrm{Fox} \mathrm{H}$ : Predicting response to omalizumab, an anti-IgE antibody, in patients with allergic asthma. Chest 125 , 1378-1386 (2004).
40. Busse W W: Anti-immunoglobulin E (omalizumab) therapy in allergic asthma. Am. J. Respir. Crit. Care M ed. 164, S12-S17 (2001).

41. Casale TB: Anti-immunoglobulin E (omalizumab) therapy in seasonal allergic rhinitis. Am. J. Respir. Crit. Care M ed. 164, S18-S21 (2001).

\section{Affiliations}

- Stephanie S Park Washington U niversity School of M edicine, Division of Allergy \& Immunology, $D$ epartment of Internal M edicine, Saint Louis, M 0 63110, USA

Tel.: +1 314454 7376; Fax: +1 314454 5140; spark@im.wustl.edu

- Sarah J Ehlenbach M edical College of Wisconsin, Section of Allergy \& Immunology, D epartment of Pediatrics, M ilwaukee, WI 53226, USA

Tel.: +1 414456 5648;

Fax: +1 414456 6487; sehlenba@mcw.edu

- Mitchell H Grayson M edical College of Wisconsin, M ACC Fund Research Center, Room 5075, 8701 Watertown Plank Road, M ilwaukee, WI 53226, U SA Tel.: +1 414456 5648;

Fax: +1 414456 6487; wheeze@allergist.com 